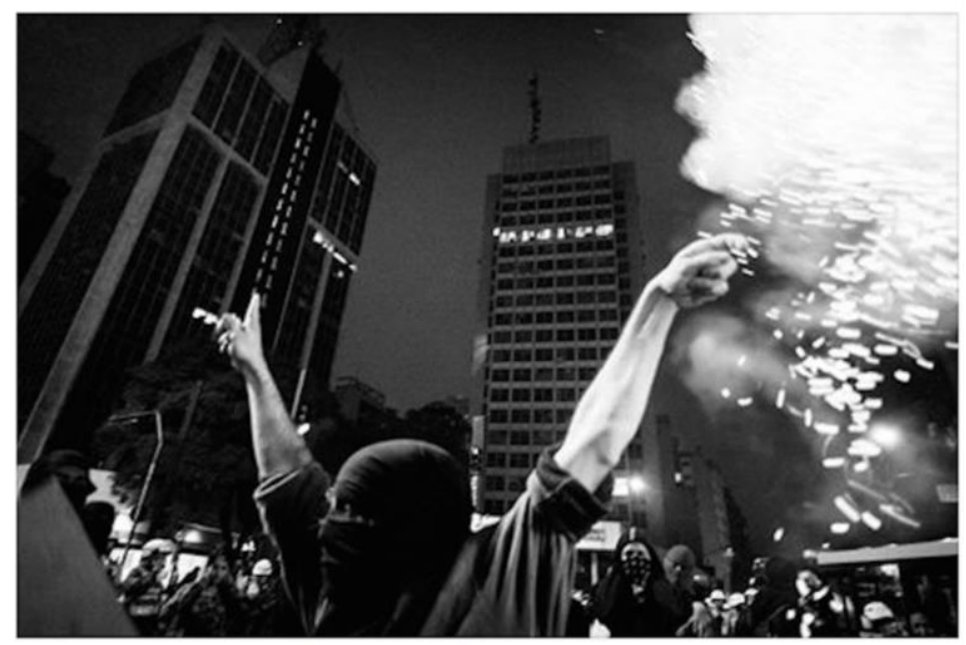

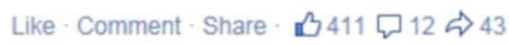

\title{
A construção da memória do sujeito contemporâneo a partir de arquivos-
}

\section{monumentos}

The construction of the contemporary subject's memory through monument archives

\section{Eliane Righi de Andrade ${ }^{1}$ Paula Cristina Somenzari Almozara ${ }^{2}$}

Resumo: Este artigo discute, por um olhar interdisciplinar, a formação da memória do sujeito contemporâneo, constituída pelos arquivos, os quais são entendidos, ao mesmo tempo, como forma de preservação de uma memória histórica e coletiva - o arquivo-documento - e como interpretação, a partir das diferentes "entradas" do sujeito no arquivo - o arquivo-monumento. Essa reflexão entende os arquivos como uma construção social que se utiliza de elementos historicizados para gerar redes de significados. Utilizando recortes (fotos e textos) das manifestações sociais de 2013 como material de análise da pesquisa, conclui-se que a memória é constituída pelas várias interpretações sobre o arquivo, produzidas na relação entre o dizer e a imagem, no tempo-espaço histórico que caracteriza um acontecimento.

Palavras-chave: Arquivo; Memória; Acontecimento; Sujeito contemporâneo; Arte.

Abstract: This article proposes, by an interdisciplinary perspective, the discussion about the constitution of the memory of the contemporary subject, memory formed by archives that are understood, at the same time, as a way of preserving the historical and collective memory - the document-archive - and as a work of interpretation, through the different "entries" that the subject does into the archive - the monument-archive. This reflection considers the archives as a social construction which uses historicized elements to produce meaning networks. Using extracts (pictures and texts) from the social manifestations that occurred in 2013 in Brazil as the analysis material of the research, we can conclude that memory consists of different interpretations of the archive, produced in the relationship between what is said and the image, in the historical time-space that characterizes an event.

\footnotetext{
${ }^{1}$ Professora e pesquisadora da Faculdade de Letras do Centro de Linguagem e Comunicação (CLC) da PUC-Campinas, com doutorado em Linguística Aplicada pela Unicamp. Email: eliane.righi@puccampinas.edu.br.

2 Artista visual, professora e pesquisadora da Faculdade de Artes Visuais e Coordenadora do Núcleo de Pesquisa e Extensão do CLC da PUC-Campinas. Doutora em Educação na Área de "Educação, Conhecimento, Linguagem e Arte" e Mestre em Artes pela Unicamp. Email: almozara@puccampinas.edu.br
} 
Keywords: Archive; Memory; Event; Contemporary subject; Arts.

Introdução

A proposta deste artigo é discutir noções teóricas de arquivo e de memória que se entrecruzam em diferentes áreas do conhecimento, de modo a estabelecer uma relação interdisciplinar entre esses estudos (discurso, artes e fotografia) para entender a formação de arquivos e da memória e sua relação com as subjetividades em construção na contemporaneidade. Observamos, pelo estudo, uma dupla injunção do papel da memória na constituição subjetiva: o desejo da manutenção e, ao mesmo tempo, o da violação dos arquivos, ou seja, há um desejo de se preservar uma memória "histórica", coletiva, mas todo acesso ao "já-dito" - memória discursiva - se dá por um novo olhar, o que torna cada gesto singular e irrepetível, ainda que condicionado pela história. Partiremos dos estudos do discurso e da desconstrução para considerações específicas sobre a constituição do arquivo na arte contemporânea e fotografia especificamente, de modo a perceber sua relação com os processos constitutivos da memória marcados pelas condições históricas que circunscrevem objetos artísticos (ou não) a seus espaços de produção e, portanto, a gestos de interpretação fundados na relação entre o velho e o novo, tornando-os acontecimentos na História.

\section{Dos arquivos tradicionais aos arquivos digitais: a necessidade da memória}

Recentemente o vice-presidente do Google e cocriador da web, Vint Cerf, em entrevista, ao correspondente de Ciências da BBC Pallab Ghosh, publicada no site da rede em 3 de fevereiro de 2015, demonstra sua preocupação com o fato de que as informações (imagens, dados, palavras) armazenadas nos arquivos digitais podem se perder na medida em que hardware e software se tornem obsoletos para "ler" as informações contidas naqueles documentos. Essa "memória" arquivada nos computadores e redes, em uma quantidade infinita e sem um sistema de organização que marque sua historicidade, caracteriza o que Orlandi (2010, p. 9) chama de memória metálica. Essa memória é marcada pela repetição, pelo acúmulo de informações que, segundo a mesma autora, gera um efeito de simulacro de memória, já que parece constituir uma "rede de filiação", mas, na verdade, é uma justaposição de fragmentos que se juntam "aqui e ali".

Para Cerf, o ato de guardar inúmeras informações virtualmente, seja nos drives de computadores pessoais, seja nas "nuvens", pode ser inócuo se tais informações não puderem ser mais acessíveis em virtude da tecnologia ultrapassada utilizada para 
arquivá-las. Dessa forma, ele compara tal ameaça a uma idade das trevas digital e, ironicamente, recomenda que as pessoas passem a imprimir suas fotos e informações mais importantes, até que se desenvolva uma tecnologia capaz de preservar cada fragmento de software ou de hardware existente, nos moldes do que ocorre num museu, mas digitalmente. Assim, sem o saber, o empresário da web parece entender a inutilidade da memória metálica, o que carece do princípio organizador da memória discursiva, em que se produz um "efeito de memória" na relação entre interdiscurso (a memória que se "esquece") e o intradiscurso (a forma que o interdiscurso se concretiza na instância da formulação).

Para falarmos sobre a relação da memória com a constituição do arquivo, partiremos da noção de museu, como sugerido por Cerf, fazendo uma analogia com o conceito de arquivo de Foucault (2004). Abordando o saber por uma perspectiva arqueológica, o autor discute a constituição dos arquivos por dois olhares: o dos documentos e o dos monumentos. Podemos inferir, a partir dessa leitura, que o "arquivo-documento" projeta-se como algo imóvel, imutável, institucionalizado e, por decorrência disso, "morto"; enquanto o "arquivo-monumento" estaria ligado a uma concepção de arquivo sempre em construção, em que podemos fazer entradas diferentes, e, portanto, realizar incursões e interpretações sob pontos de vista também diversos, marcados pela historicidade. Dessa forma, podemos estender para as artes essas relações de sentido que Foucault estabelece com o campo discursivo, especificamente tratando-se da arte contemporânea baseada em "apropriações" de objetos outros ou de objetos de arte, e para a fotografia ${ }^{3}$, de modo especial, ao "retirá-la" de um plano documental para "inseri-la" em um campo estético.

Nesse sentido, a ocorrência de um objeto artístico, pode ser concebida - em analogia com a perspectiva discursiva de Foucault (2004) - como um novo acontecimento, já que o arquivo remete a um conjunto de enunciados naquilo que ele tem de repetível e de novo, caracterizando-se como acontecimento ${ }^{4}$.

\footnotetext{
${ }^{3}$ A fotografia vista como um suporte arquivístico por natureza.

${ }^{4}$ A noção de acontecimento (discursivo) em Foucault $(2002 ; 2004)$ remete à articulação entre passado e presente, pois o que é dito no passado tem efeitos no presente, causando uma nova interpretação daquele. O presente é, pois, constituído tanto da memória, daquilo que é repetível, quanto daquilo que é inédito (dado pela característica de novidade do acontecimento), rompendo com a continuidade do passado. $\mathrm{O}$ acontecimento, portanto, está relacionado às condições de sua aparição e aos efeitos de sentido, mediante as possíveis interpretações que lhe são atribuídas pelos sujeitos na história, no momento único da enunciação. Daí remeter tanto ao novo e ao singular, quanto ao velho e repetível (FOUCAULT, 2002; 2004).
} 
A obra de arte contemporânea, ao se apropriar de objetos outros ${ }^{5}$, gera um novo acontecimento, uma nova obra, a qual é "ressignificada" dentro de outras condições de produção, reunindo, assim, ao mesmo tempo, as características repetíveis de um exemplar, mas também implicando a construção de uma nova identidade, num sistema que Freitas (2013) denomina de alográfico em oposição ao autográfico (aquele que rege as pinturas, por exemplo, cuja natureza clamaria por uma história dos processos produtivos do artista, numa relação corpo, objeto e tecnologias). Dentro do regime autográfico, portanto há uma ideia de ordem determinada pelo artista e que torna a obra o que ela "é". No sistema alográfico, por outro lado, há a possibilidade ainda de mais de uma ocorrência de um mesmo "objeto artístico", havendo, porém a necessidade de um "sistema de notação (...) para registrar de modo suficiente a identidade da obra" (FREITAS, 2013, p. 22). Assim, para o objeto ter essa nova identidade - ser outro - é preciso ser transposto para um museu, por exemplo, lugar que configuraria ao objeto, então, sua nova natureza artística, já que há um sistema de regras delimitadas também pelo autor e pela instituição, ou seja, uma “ordem do discurso" (FOUCAULT, 2002).

Retomando, nesse momento, as reflexões sobre o dito de Vint Cerf sobre a construção de arquivos digitais, associar o arquivo digital a um museu - como ele o faz implica, também, um espaço e um tipo de organização, remetendo-nos a outro conceito de arquivo, desenvolvido por Derrida (2001), a partir de um olhar desconstrutivista. Para o autor, "não há arquivo sem espaço instituído de um lugar de impressão. Externo, diretamente no suporte, atual ou virtual" (DERRIDA, 2001, p.8), pois há a exterioridade de um "lugar", em que se estabelece uma técnica de consignação, de reunião dos documentos, bem como um "lugar", uma posição de autoridade para essa organização, que pode ser a de uma instituição, a qual representa um discurso de poder em relação à sociedade que legitima esses lugares. Em outras palavras, é preciso estar inserido numa “ordem do discurso", como afirma Foucault (2002).

Derrida (2001), em sua reflexão sobre arquivo e memória, traz à discussão a "origem" grega do termo arquivo (arkheîon), que remete inicialmente ao endereço (portanto, um lugar) daqueles que tinham o comando e que representavam a lei (portanto, um grupo de indivíduos). Eram eles os arcontes, os primeiros guardiões dos documentos oficiais. Dessa forma, voltamos à ideia de arquivo como um sistema de organização dos documentos, como já afirmara Foucault (2004), mas que implica

\footnotetext{
${ }^{5}$ Freitas (2013, p.20) refere-se aos chamados ready mades de Duchamp, que desmistificam a ideia de autoria e originalidade dos trabalhos ditos autográficos.
} 
também um grupo ou indivíduo responsável por guardar, permitir (ou não) o acesso aos documentos e, mais ainda, "interpretá-los", afastando-nos do princípio meramente técnico de organização (que se articula à memória metálica) e possibilitando uma passagem do privado para o público. Assim, inferimos também um processo de "consignação" dos arquivos artísticos, reunidos e organizados nos museus por seus sistemas de classificação e interpretação.

Segundo Derrida (2001), ainda, nesse movimento invisível de organização, manutenção e divulgação da informação, busca-se, ao mesmo tempo, a preservação "total" de uma memória, de um passado - um desejo de memória, como afirma o autor - bem como o desejo de divulgá-la para o futuro, podendo torná-la pública e não mais restrita aos que têm poder sobre a informação guardada. Portanto, o ato de arquivar seria, ao mesmo tempo, de natureza conservadora e revolucionária, pois volta-se ao passado com os olhos no futuro. Derrida, neste momento, refere-se, mais especificamente, aos arquivos institucionais, sob a guarda das diversas instituições e de seus "arcontes", o que permite estabelecer relação também com os sistemas de atribuição, organização e divulgação das artes, com seus museus, galerias e exposições.

De algum modo, Vint Cerf, na declaração que trouxemos acima, ao se referir aos arquivos digitais em sua efemeridade, faz uma analogia oposta à concepção de escrita proposta por Platão em Fedro - passagem mencionada em outra obra de Derrida (1997) - em que o filósofo grego expõe a secundarização da escrita, pois ela não garantiria a verdade e a autoridade do que é dito e de quem o diz, servindo-se à mera memorização "decorada", praticada então pelos sofistas. No dizer do entrevistado de Cerf, pelo contrário, deve-se valorizar o que está impresso (como se fosse uma "escrita"), pois isso garantiria a continuidade da memória, a preservação da informação e do "documento" para a posteridade. Isso parece paradoxal em se tratando do mundo virtual, pois ao recomendar a impressão de imagens e textos que estão nas memórias eletrônicas dos computadores, nas nuvens compartilhadas da rede, o entrevistado parece valorizar aquilo que se encontra impresso (em algum suporte material "real") como uma garantia de se manter uma memória "desejável”.

Podemos concluir, no entanto, que a "mera" existência de arquivos - textos, informações, registros, fotos - não garante que as informações nele contidas sejam “decifráveis", lidas e interpretadas, pois, como postula Derrida, em seus estudos sobre o tema, sua existência não implica na possibilidade de divulgar o que neles está contido, nem em sua preservação, a não ser que aqueles que os "controlam", os "organizam" 
permitam seu acesso (lembremo-nos das bibliotecas na Idade Média como um exemplo de inacessibilidade aos arquivos).

Partiremos, agora, nesse percurso teórico, para a discussão da formação de "arquivos" de memória no e pelo sujeito, pensando no modo como os processos de construção da memória relacionam-se, no sujeito, às formações inconscientes em interação com os processos sócio-históricos de construção da memória descritos até aqui.

\section{A relação memória discursiva e inconsciente}

Trazemos o subsídio da psicanálise freudo-lacaniana para tal discussão, pois, por tal viés, a memória do sujeito se dá pela impregnação de marcas, ou seja, pela impressão de significantes no inconsciente do sujeito. Assim, para a psicanálise, a memória para ser trazida à lembrança deve ser antes esquecida e só depois pode ser "acionada", inconscientemente pelo sujeito, de modo que ela possa ser significada na relação com outros significantes no momento de sua emergência.

Cabe-nos, desse modo, entender a "impressão" para além da noção concreta e material abordada pelo entrevistado que foi trazido no início dessa discussão. Pensamos, então, no processo de impressão da memória no inconsciente do sujeito, comparando-o a uma cicatriz, uma tatuagem, ainda que outras marcas possam ser sobrepostas a essas em novas relações significantes, em diferentes gestos de interpretação. Tais marcas podem ser acessadas pelo sujeito de modo completamente "involuntário", ou seja, o acesso ao "arquivo" subjetivo é de natureza inconsciente e como tal é o inconsciente que chama tais "impressões" à presença, pois são processos que se formam no momento de sua emergência, constituindo, assim, "acontecimentos". Essas "marcas" também não deixam de ser "virtuais" - embora tenham efeito no real - se pensarmos o inconsciente como uma construção baseada numa cadeia de significantes semelhante a uma linguagem em que se operam as leis do deslizamento e da substituição (LACAN, 1985a) e que, portanto, estão em constante movimento em relação a essa cadeia.

Para Freud (1996), em um de seus primeiros escritos, de 1896, a memória constitui-se no aparelho psíquico do sujeito e se dá em etapas que se relacionam e se sucedem (percepção - registro - inconsciência - pré-consciência - consciência), embora não obrigatoriamente seguindo todos os passos, já que nem toda percepção do mundo, das coisas, dos fatos, se transforma em uma representação (campo do inconsciente), pois seu registro pode se submeter a um recalcamento (não ser simbolizado) ou ser 
"esquecido", sofrendo um processo de "rearranjo" quando acionado pelo sujeito em um determinado momento, tornando-se, então, "lembrado".

Pretendemos reforçar aqui o fato de que nem toda "memória" é recalcada pelo sujeito. Ela pode ser apenas "esquecida”, uma vez que os processos de organização são inconscientes e acontecem a posteriori, ou seja, depois que já existe um saber armazenado em forma de representação - quando isso foi possível - e o sujeito pode tornar tal "memória" consciente, mediante seu acionamento a partir do campo do inconsciente, onde tal representação de memória encontra-se em relação a uma cadeia de significantes. Essa cadeia de associação se dá na e pela história do sujeito. A representação, então, adquire sentido sempre num movimento posterior de acionamento. No recalque, por outro lado, não há a aparição do significante (representação) a partir da percepção, pois há uma "falha" na passagem de uma etapa para outra do sistema, dando origem a um sintoma, o qual não passou pelo processo de simbolização e "jaz" no campo do real, retornando sempre em forma de uma repetição autômata. A noção de registros (real, imaginário e simbólico) que aqui utilizamos faz referência à teoria lacaniana (LACAN, 1985b) do nó borromeano, que explica a constituição do sujeito (psicanalítico) por meio de círculos enodados representando tais instâncias.

Retornando a Freud (1996b), agora em outro texto em que discorre sobre o "bloco mágico", o autor utiliza-se de tal tecnologia para exemplificar o funcionamento da "gravação" das memórias no aparelho psíquico, fazendo uma analogia entre os desenhos que são realizados em sua superfície de celuloide com a constituição dos traços mnemônicos no sujeito. $\mathrm{O}$ autor observa que nessa superfície são escritos traços que podem ser apagados simplesmente pelo fato de se desgrudar a superfície de celuloide da página encerada à qual é fixada, fazendo uma analogia com as múltiplas percepções que são captadas pelo sujeito através dos sentidos e que jazem como marcas "sem sentido". No entanto, nessa segunda superfície encerada podemos observar que os traços continuam presentes, ainda que "esquecidos" em seu momento de produção. Esse conjunto de traços permanentes, ainda que não compreensível ou recuperável imediatamente, constitui a memória do sujeito, cuja natureza é inconsciente. Daí tais traços não serem "recuperados" por sua "vontade", mas pela associação significante que eles produzem na cadeia de significantes.

Finalmente, gostaríamos de relacionar o conceito de memória discursiva com interdiscurso e colocá-los em diálogo com as discussões teóricas produzidas até aqui. É valioso aqui trazer o conceito de interdiscurso, desenvolvido por Pêcheux (1999; 1990), 
que o caracteriza como o conjunto de todas as possibilidades do dizer, tanto do que foi já dito quanto do que poderá vir a ser, mas sempre submetido a uma ordem do discurso, em que as formações discursivas regulam historicamente a circulação desses dizeres e dos sentidos que deles derivam. Assim, segundo Orlandi (1999, p.63), a produção de sentidos estará sempre sujeita a mecanismos de interdição, pela "censura e pela força", o que faz determinados sentidos parecerem impossíveis. Esse espaço do interdito na perspectiva discursiva guarda certa relação com o conceito de recalcado da psicanálise, pois há mecanismos que atuam sobre ele de modo a não torná-lo consciente, embora exista como possibilidade no real.

Embora tais teorias sobre a memória tenham pontos de divergência, de dissenso, acreditamos que, para essa reflexão, podemos atar tais redes do pensamento para provocar uma reflexão sobre os processos de formação de memória, que produzem "arquivos" de natureza diversa, provocando relações significantes para este estudo que se estende para o campo das artes e da fotografia, relacionando a memória ao arquivodocumento e monumento.

Podemos afirmar, ainda, que a memória vai se utilizar de associações que são construídas nas diferentes linguagens e que fazem uso das mais diversas tecnologias para tentar "fixar" representações significativas. Rose (2001a, p.162), que se utiliza dos estudos deleuzeanos para discutir a memória, afirma que o sujeito faz uso de diferentes tecnologias para produzir e organizar uma "história" de si. Ele aponta as fotos, os relatos familiares, os documentos, as cartas, como diferentes tecnologias para criar uma "biografia psicológica" autorizada do eu, na tentativa de controlar a constituição de uma memória. Através desses recursos, o eu "recupera" fragmentos de uma memória "esquecida", organizando-a segundo uma certa lógica, criando, assim, uma história de si e do outro. Aquilo, porém, que o sujeito controla não é a memória inconsciente. São arquivos cujas "informações" estão liberadas de amarras, de recalques, por isso fazem parte dessa história autorizada de si, buscando constantemente fixar o registro do que desapareceu e não está mais presente, mas que o sujeito deseja "reter", preservar.

Essas noções de memória permitem que dialoguemos com diferentes áreas do saber e entendamos o arquivo como uma construção do sujeito que se dá sempre num tempo e espaço. 


\section{Arte contemporânea e fotografia: documento ou monumento?}

Caminhando, então, para outros espaços discursivos em que se dialoga a todo o momento com a memória para se produzir efeitos de sentido outros, pensamos como a produção de arte na contemporaneidade se vale também de processos de ressignificação e, portanto, de estratégias de apropriação, com as quais estabelece "os contornos de uma tipologia da pós-produção" (BOURRIAUD, 2009, p. 9). Nesse aspecto, o conceito de "pós-produção" em si nos interessa por caracterizar a apropriação de um termo técnico utilizado nos processos da televisão, do cinema, da música e em outros segmentos, como forma de trabalhar ou dar um tratamento final a um material pré-existente (Idem, ibidem).

Pensamos na tipologia da pós-produção elencada por Bourriaud para confrontála com elementos que potencialmente se referenciam ao arquivo, o qual foi aqui descrito como uma espécie de agrupamento de coisas e/ou elementos salvaguardados por alguém ou não, ao que acrescentamos, em relação às artes, a condição que permita que se faça dele uma disposição para o uso, não entendido aqui em sua natureza utilitarista, mas em seu caráter de exercício ou prática para "reprogramar obras existentes", "habitar estilos e formas historicizadas", "usar imagens", "utilizar a sociedade como um repertório de formas", "recorrendo à moda e aos meios de comunicação" (BOURRIAUD, 2009, pp. 9-12). Essas práticas contemporâneas realizadas sobre os objetos artísticos (ou para transformá-los em tais objetos) seriam, segundo o autor, modos de enfrentamento que causam:

uma profunda transformação no estatuto da obra de arte. Ultrapassando seu papel tradicional como receptáculo da visão do artista, ela funciona como um agente ativo, uma distribuição, um enredo resumido, uma grade que dispõe de autonomia e materialidade em diversos graus, com uma forma que pode variar da simples ideia até a escultura ou o quadro (BOURRIAUD, 2009, p.17)

Bourriaud permite que pensemos na ideia da "cultura do uso" relacionada, por exemplo, à influência duchampiana ${ }^{6}$ que determina que o sentido da obra advém de uma colaboração, ou mesmo de uma negociação, entre o artista e as pessoas que observam a obra (BOURRIAUD, 2009, p.17). Assim, "usar o objeto é interpretá-lo" (BOURRIAUD, 2009, p.17) e essa é uma questão sintomática em se tratando da forma como os artistas contemporâneos se valem da noção de arquivo propriamente dito, que

\footnotetext{
${ }^{6}$ Marcel Duchamp (1887-1968) afirmava, segundo Bourriaud (2009, p. 17), que: "são os espectadores que fazem os quadros".
} 
se transforma em um catalisador de significados e um signatário de uma poética visual baseada nos conceitos de pós-produção e de suas tipologias.

Para ilustrar esse processo de reinterpretação que faz uso da memória como um processo de constante (res)significação nas artes, particularmente da fotografia, trazemos como exemplo a "redescoberta" que Aby Warburg faz de imagens antigas em seu inacabado Mnemosyne Atlas (1924-1929). Didi-Huberman (2013), comentando sobre esse trabalho, afirma que Warburg, nesse processo, realiza a "subversão" do tempo histórico em um tempo psíquico, corroborando a ideia de memória como um processo também inconsciente, ainda que historicamente condicionado.

Melhor que o eterno retorno nietzschiniano (a montante), a repetição freudiana (a jusante) permite captar com precisão o que Warburg procurava na temporalidade "sismográfica" e "dinamográfica" das imagens. O que Mnemosyne almeja está justamente "além do princípio do prazer": não é a simples beleza, não é a rememoração como tal muito menos a coleção de lembranças infantis da arte ocidental -, e sim o próprio modo de instauração do tempo na imagem (DIDIHUBERMAN, 2013, p.276)

Artistas como Bleda \& Rosa (2007) nos dão uma pista sobre como essas questões temporais e mnemônicas afetam a instauração da obra na contemporaneidade, afirmando, em seus escritos, a construção poética "ao redor da memória", em relação à fotografia:

Percorrer um lugar ou uma fotografia (grifo nosso), pelo menos em determinadas ocasiões, deveria ser um ato consciente e ativo de onde se constrói a própria experiência, sobretudo se partirmos da ideia de que a paisagem, real ou representada, está no olhar de quem contempla ou transita e não no lugar que motiva em si esse pensamento. (BLEDA \& ROSA, 2007, p.177)

Dessa forma, percebemos que o sujeito é "afetado" pelas imagens (nesse caso, as fotos) de forma diversa e singular, constituindo seu próprio arquivo.

Didi-Huberman (2010) aprofunda mais ainda essa discussão, trazendo à tona a noção para as artes de "atlas". Ao organizar a exposição em Madri "ATLAS ¿Cómo llevar el mundo a cuestas?", afirma em entrevista que partiu de uma concepção justamente inspirada em Aby Warburg, sintetizando como a arte se vale da ideia de arquivo, mas que se amplia no conceito de atlas, o qual confere aos objetos a força sígnica visual que o autor não acredita "caber" na noção teórica de arquivo:

Esta exposição trata do destino de uma forma de conhecimento visual chamada atlas, baseada no trabalho de Aby Warburg, um historiador de 
arte e teórico alemão, que resultou em um grande momento, uma grande virada para entender o que são as imagens. A exposição fala de uma proximidade entre este trabalho de conhecimento e o trabalho de muitos artistas dos séculos XX e XXI que utilizaram a forma de atlas, na qual podemos reconhecer uma história da imaginação humana. Geralmente, quando se expõe um arquivo, não se vê nada, o real uso do arquivo é algo com o que se trabalha durante semanas após semanas, meses após meses, anos após anos, é longo. Em contrapartida, o atlas é uma apresentação sinóptica de diferenças: se vê uma coisa e outra coisa completamente distinta que é colocada ao lado. O objetivo do atlas é entender a ligação entre as coisas, que não é uma ligação baseada na similaridade, mas sim uma conexão secreta entre imagens diferentes. Por isso um atlas é uma ferramenta muito mais visual do que pode ser qualquer arquivo. Atlas é um trabalho de montagem em que se unem tempos distintos. É um choque. (DIDI-HUBERMAN, 2010, 1'41)

De fato, pensamos numa possível associação entre o atlas e os processos mnemônicos inconscientes de cada artista, de cada sujeito que (re)lê - pensando numa perspectiva discursiva - uma obra ou um conjunto de objetos artísticos (fotos), constituindo uma cadeia significante singular, cujo processo de "organização" lhe é desconhecido, pois não há acesso à "natureza primeira" de qualquer obra de arte. Dessa forma, contesta-se a ideia de um "original", devido aos diferentes modos de classificação, aos gestos diversos de interpretação daquele que organiza e que interpreta. Didi-Huberman aborda a questão sob o ponto de vista do teórico que toma o arquivo como fonte de informação e não necessariamente como ferramenta visual, como ele mesmo afirma. Para o artista, a questão se coloca de uma maneira diferente, naturalmente engendrada, em função do próprio diálogo visual em que ressoam a materialidade e o pensamento no processo de produção artística, que grosso modo compele à produção de um arquivo de imagens e projetos.

Diante disso, arquivo e atlas se constituem como formas artísticas pelo modo como os objetos e imagens são instaurados e como seus significados são alterados em função do "jogo" de justaposição e montagem a que são submetidos, levando em conta o "tempo na imagem", mais do que propriamente a imagem em sua pretensa origem indicial. Isto valida ou revela a conexão com as propostas contemporâneas ligadas às tipologias da pós-produção que, enfim, trabalham a reprogramação de obras existentes e o uso de estilos e formas historicizadas.

Segundo Rosengarten (2012), as fronteiras entre o documental e o artístico na fotografia são quebradas, em especial se considerarmos que o catálogo, o arquivo e a enciclopédia se apresentam de modo difuso mas que, no entanto, anseiam 
paradoxalmente por um desejo de "totalidade abrangente" (ROSENGARTEN, 2012, p. 12), como já mencionara Derrida (2001).

O que se percebe, segundo Rosengarten (2012, p. 13) é uma "tensão entre o histórico e o pessoal", o que nos remete às imagens fotográficas como "ponto axial entre as esferas pública e privada" (2012, p. 13), convencendo-nos de que a fotografia é um elemento arquivístico por natureza - no sentido "documental" que Foucault lhe designaria -, caracterizando-se, assim, como uma tecnologia usada para construir uma memória coletiva, mas também um elemento artístico, quando remete ao espaço da singularidade do sujeito que vê e (re)interpreta.

Segundo Damisch (2012, p. 11) a fotografia:

\begin{abstract}
opera em outros espaços de discurso que não são estritamente artísticos: o espaço da reportagem, da viagem, do arquivo e até da ciência. A aura algo suspeita que lhe confere hoje seu ingresso no museu, o verdadeiro culto de que os vintage prints são objetos que doravante são como a paródia inversa do processo dessacralização da obra de arte que teria chegado ao seu término com a invenção da fotografia: o valor de exposição leva vantagem sobre a função de documentar. O resultado é que acreditamos dispor da fotografia como as obras de arte conservadas no museu, quando ela continua evidentemente a dispor de nós, como o revela a imagem que nos assalta de repente, nos punge na hora da leitura dos jornais ou quando irrompe de nosso arquivo particular.
\end{abstract}

Esta citação de Damisch corrobora, de certa maneira, com o que Rosengarten considera uma "viragem arquivística", a qual pode ser vislumbrada pela paradigmática obra "Boîte en Valise" (Caixa-valise) de Marcel Duchamp - em que o artista faz reproduções em pequena dimensão de suas principais obras - e aproxima-se da noção de arquivo de Michel Foucault "segundo a qual o arquivo faz a mediação entre tradição e esquecimento" (ROSENGARTEN, 2012, p. 30), entre a memória fossilizada que constrói o arquivo documento e a memória por vir, a ser construída em cada gesto de interpretação, a qual associaríamos à formação do arquivo-monumento e à ideia, ainda, de "museu imaginário" de Malraux (2011). Assim, a obra de Duchamp estaria conectada ao desejo ou interesse do artista em por abaixo "os muros institucionais e conceituais que delimitam a definição de objeto artístico e do criador desse objeto"(ROSENGARTEN, 2012, p. 26). 
A fotografia, no caso específico da obra citada, com sua configuração híbrida entre documento e monumento, desestabiliza o regime autográfico, já comentado no início deste texto, e faz com que Duchamp inscreva-se nas artes por meio do uso deliberado de processos que consideram a ruptura ou a ausência de processos tradicionais na instauração da obra, abrindo espaço para novos olhares, circunscritos por outras condições histórico-sociais.

Finalmente, Rosengarten (2012, p.31-32) traz a distinção de Foucault (2004) entre método e sistema para pensar arquivo não mais como um repositório cuja função é ser usado para uma futura consulta (portanto, além da aplicação de um método), mas também em relação a um "contra-arquivo fantasma de lixo", permitindo a organização de um outro sistema de arquivamento, com aquilo que não se quer e que, por esse motivo, seria descartado. Dessa forma, teríamos um arquivo constituído também do "recalcado", fazendo uma analogia com a memória freudiana. Esse sistema de organização da memória confronta-se com aquele postulado por Rose (1996), que privilegia as "narrativas" (e suas imagens) autorizadas para a construção das "ficções de si". Entendemos a memória, então, nesse espaço do "entre", em que processos conscientes e inconscientes levam a releituras das impressões mnemônicas.

É interessante, ainda, nesta discussão sobre arquivo pensar sobre uma outra noção - a de "contra-arquivo" - que tem sido proposta por artistas como Thomas Sauvin. Este artista, que é um editor e colecionador de fotos que vive em Pequim e é consultor do Archive of Modern Conflict (AMC), é descrito como um fotógrafo colecionador, porque sua prática está baseada na coleta de fotografias realizadas por outras pessoas. Em seu projeto intitulado Silvermine ${ }^{7}$, ele visita locais de reciclagem em Pequim - muitos deles clandestinos - que processam material fotográfico para extrair o nitrato de prata presente na composição dos filmes e negativos. Sauvin recupera, então, certos negativos que cobrem um período de aproximadamente 20 anos, entre 1985 até 2005 - ano esse em que a fotografia digital começou a ser usada na China -, e cria a partir dessa cadeia de fotos uma narrativa visual sobre as pessoas comuns retratadas em situações do cotidiano. Nesse caso, o arquivo se constrói também por aquilo que foi esquecido, abandonado ou que se deseja "esquecer" e neste movimento de criação do que chama "contra-arquivo" podemos pensar na geração do arquivo-monumento, que traz à tona também o que foi descartado na construção da - ou de uma - história.

\footnotetext{
${ }^{7}$ Thomas Sauvin: Silvermine. London: Archive of Modern Conflict, 2013. ISBN 978-0-9570490-1-7. Five albums each containing 20 prints. Edition of 200 copies.
} 


\section{A fotografia como arte e/ou documento: diferentes acontecimentos}

Se fizemos até aqui um percurso reflexivo sobre a constituição da memória, procurando relacionar diferentes olhares teóricos sobre o arquivo, ampliando sua significação para além do arquivo-documento, trazemos, neste momento, um recorte discursivo composto de texto e fotografia, o qual foi retirado de uma mídia digital, com o qual podemos fazer gestos de interpretação sobre o deslocamento da ideia de arquivodocumento para arquivo-monumento. Este recorte retrata um momento das movimentações que ocorreram a partir de junho de 2013 e faz parte de um conjunto maior de recortes discursivos que buscam empreender alguns efeitos de sentido para esse movimento social e para a construção das subjetividades no mundo de hoje.


Like · Comment - Share - $3411 \square 12 \Rightarrow 43$

Foto de Caio Cestari. Ato Milhões de máscaras, 05/11/2013. Fonte: Página da Mídia Ninja no Facebook. Acesso em 6/11/2013.

No recorte, observamos a foto concebida em preto e branco, que estabelece um contraste entre o fundo escuro e fragmentos iluminados, provavelmente causados pela luz ou pequenas explosões (fogos, coquetéis-molotovs). Nela um sujeito, em primeiro plano, com o rosto e cabeça cobertos, parece comemorar, em meio à multidão. Como se trata de uma foto que se refere a uma das manifestações ocorridas, o momento retratado parece "representar" uma "festa", talvez de cidadania. Os braços erguidos dessa pessoa 
ao centro, em primeiro plano, parecem reger uma grande orquestra imaginária (seriam os sons da rua, dos manifestantes, do "gigante adormecido", como acusa a memória ainda recente de um Brasil bem sucedido?)

O texto que acompanha a foto ratifica nosso gesto de interpretação: "Ato Milhões de Máscaras", o que sugere a multidão, numa grande festa, como num baile de carnaval, mas também onde as pessoas estão em "ação" (ato), o que sugere mobilização (movimento) social.

Se a foto de Caio Cestari, publicada na página da Mídia Ninja e compartilhada no Facebook, tem, sem dúvida, um caráter documental, registrando momentos das mobilizações urbanas que se iniciaram, aparentemente, pelo protesto ao aumento da passagem de ônibus em São Paulo, fazendo com que seja parte de um acontecimento discursivo, que o condiciona à História, também pode ser "lida" em sua natureza artística, permitindo outras "entradas", em que o tempo se caracteriza como um "tempo da imagem", salientado por Didi-Huberman (2013), desafiando o olhar do leitor (DAMISCH, 2012) para uma interpretação que atravessa o espaço documental.

Tal fato se comprova, segundo Tosetto (2015), pois há algumas fotos da Mídia Ninja que estão presentes também no acervo do Museu de Arte Moderna e que, portanto, foram elevadas a objetos artísticos, sendo interpretadas segundo novos olhares, com novos propósitos e dentro de novas condições de produção, habitando estilos e formas historicizadas para compor novos repertórios, como diria Bourriaud (2009).

Selecionamos, então, uma das imagens que fazem parte desse acervo, em que notamos a presença de muitos traços em comum com a foto anterior, publicada na mídia digital jornalística (a luz, o contraste preto e branco, o plano principal ressaltando semblantes na multidão), os quais podem ter elevado a foto a um objeto artístico, segundo os "arcontes" das artes: 


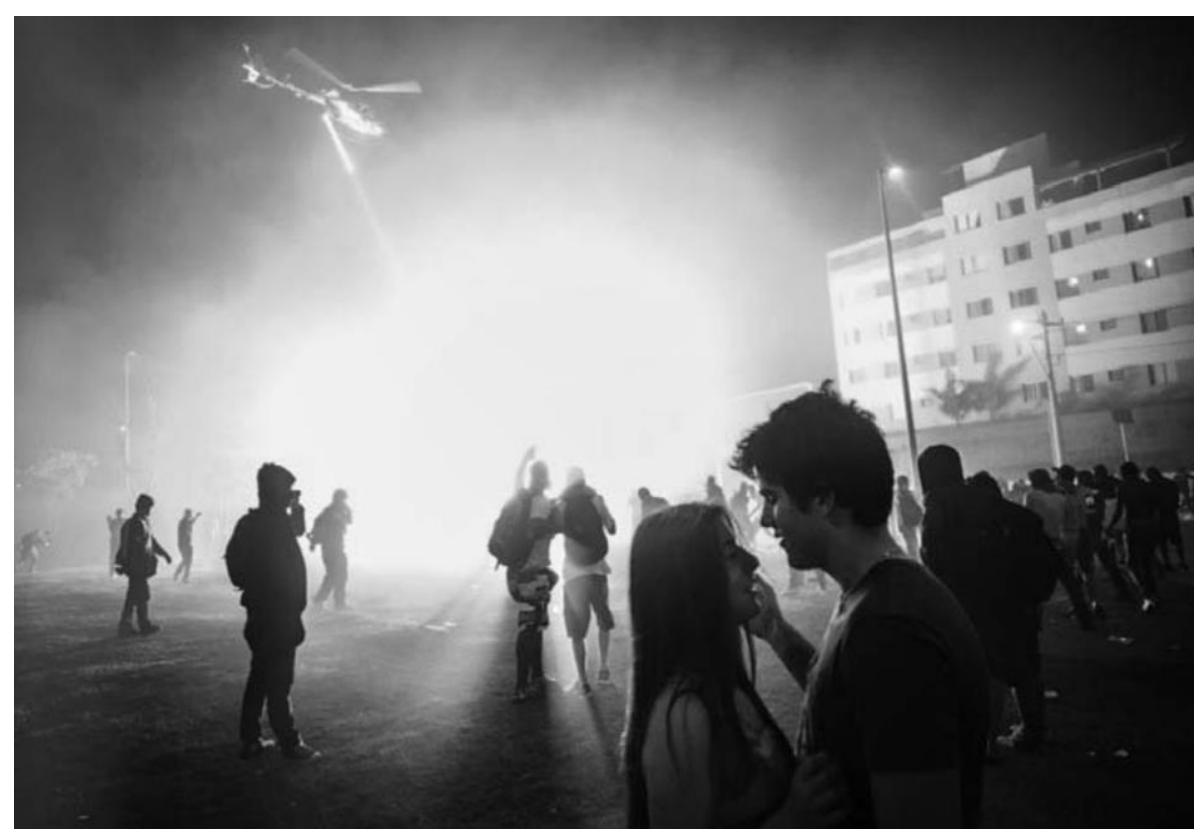

Ruas de junho, 2013/2014. Fonte: Acervo MAM-SP apud TOSETTO, 2015, p.37.

Assim, tais fotos podem coabitar o arquivo enquanto documento, de caráter jornalístico, e o arquivo artístico (obra de arte). É interessante salientar, ainda, que tal mídia digital revela também a diluição da autoria que se dá pelas redes, outro ponto a ser destacado ao se pensar na ruptura dos sistemas autográficos nas artes (notamos, por exemplo, que a segunda foto não traz a "origem", autoria de quem a concebeu, sendo identificada apenas pela data e por um título que a nomeia como objeto artístico. Assim, ela pode ser encarada, ainda, como um produto da chamada "cultura convergente" (JERKINS, 2009 apud TOSETTO, 2015).

Em relação a seu objetivo, a Mídia Ninja é uma fonte alternativa de informação, que funciona como um consumidor que se transforma em criador, convidando seu leitor a se tornar um "ninja" também (TOSETTO, 2015), ou seja, a produzir e consumir, o que sugere uma analogia com o objeto artístico que se coloca à disposição para o uso, como enfatizado por Bourriaud (2009).

\section{Reunindo as partes sem formar um todo}

Pensamos na construção da memória por intermédio da (re)interpretação dos arquivos, constituídos de imagens e dizeres, em que os fragmentos de memória que os compõem constroem relações de sentido, num contexto histórico-social, verticalmente. $\mathrm{O}$ arquivo possui natureza dupla: a de garantir uma memória e, também, por constituirse de atos de interpretação, a de violentar o que é guardado, num movimento de constante releitura. Essa ideia de arquivo se delineia a partir da distinção foucaultiana de 
arquivo-monumento e arquivo-documento, que pode ser estendida para além do campo discursivo da linguagem verbal, instaurando-se no campo das artes, particularmente da fotografia.

Como construção singular do sujeito, a memória produz efeitos de sentido que tentam produzir uma ficção controlada de si, dando a ilusão de uma história completa e sem rupturas. Quando pensamos nos arquivos que se construíram na História, percebemos que sua organização é sempre permeada por uma ordem do discurso, em que se deseja também certo controle sobre a interpretação. No entanto, mais uma vez, intuímos que não há como controlar as interpretações, pois o arquivo só vive de suas releituras, senão, morre. Assim, manutenção e violência são características do arquivomonumento, geradas pelo movimento de revisitação e pelo desejo contínuo de trazer à presença o que está ausente (o que decerto move também os espíritos tecnológicos digitais, como o do entrevistado que abriu nossas discussões aqui!).

Nas artes, a ideia de arquivo-monumento vem ao encontro dos objetivos da arte contemporânea, em que mais do que se produzir um objeto artístico, subverte-se a ordem do discurso autográfico, propondo-se uma apropriação "violentadora" de objetos outros, os quais podem, inclusive, assumir seus duplos, os clones de si mesmos, em reproduções alográficas, que também estão sujeitas à autorização dos artistas e dos museus, lugar em que são elevadas a objetos de arte. Na fotografia, a interpretação singular dos arquivos permite também ir além da foto como tecnologia documental, já que, ao ser erigida como objeto de arte, num olhar que remete tal arquivo à ideia de monumento, a relação com o tempo é da ordem do subjetivo. Dessa forma, a arte contemporânea valoriza o movimento de interpretação que circunscreve o objeto (obra de arte, fotografia) a novas condições de produção demarcadas pela história e cultura e pelo olhar do outro.

Por último, há de se pensar sobre como enfrentar os "fantasmas" do arquivo, entendido como o elemento indesejável, que talvez se tente silenciar, na construção dos processos da memória, permitindo que haja espaço para que este elemento recalcado possa ascender a um lugar "sublime" na organização dos arquivos da humanidade e do sujeito.

Dessa forma, acreditamos que a memória pode ser encarada como o movimento constante de ressignificação das dicotomias logocêntricas, em que razão e arte coexistem, real e virtual se interferem mutualmente e em que a visão de arquivodocumento e monumento sejam concomitantes, pois são modos diferentes de se 
representar e interpretar o mundo e de se construírem memórias, sempre em sua forma plural.

\section{Referências}

BLEDA \& ROSA. "Un paseo pola memoria ou como pensar a paisaxe". IN: Paseantes, Viaxeiros, Paisaxes. Xunta de Galicia: Centro Galego de Arte Contemporánea, 2007. pp. 177-182.

BOURRIAUD, N. Pós-produção, como a arte reprograma o mundo contemporâneo. São Paulo Martins Fontes, 2009.

CORREIO, C. F. R. G. V. Michel Foucault: a genealogia, a história, a problematização. In Prometeus. Ano 7 - Número 15 - Janeiro-Junho/2014.

DAMISCH, H. "A partir da fotografia". IN: KRAUSS, Rosalind. O Fotográfico. Barcelona: Editorial Gustavo Gili, 2012. pp. 7-13.

DERRIDA, J. Mal de arquivo: uma impressão freudiana. Rio de Janeiro: Relume Dumará, 2001.

DERRIDA, J. A farmácia de Platão. São Paulo: iluminuras, 1997.

DIAS, C. Memória metálica. In Endice Enciclopédia Discursiva da Cidade online. Disponível em <http://www.labeurb.unicamp.br/endici/index.php?r=verbete/view\&id=119>. Acesso em 2 de nov. 2015.

DIDI-HUBERMAN, G. A imagem sobrevivente, história da arte e tempo dos fantasmas segundo Aby Warburg. Rio de Janeiro: Contraponto, 2013.

DIDI-HUBERMAN, G. ATLAS ¿Cómo llevar el mundo a cuestas?". Museo Nacional Centro de Arte Reina Sofia, Vídeo depoimento do comissário da exposição Didi-Huberman, 2010. Acessado em: 07/02/2015. Disponível em: https://youtu.be/WwVMni3b2Zo

FOUCAULT, M. A arqueologia do saber. Rio de Janeiro: Editora Forense Universitária, 2004.

FOUCAULT, M. A ordem do discurso. 8a . ed. São Paulo: Edições Loyola, 2002.

FREITAS, A. Obra expandida: as vanguardas e o regime alográfico. In ARS, ano 11, n 21, 2013.

FREUD, S. Carta 52 (a Fliess). In Ed. standard bras., vol. XIX. Rio de Janeiro: Imago, 1996a (CD Rom).

FREUD, S.Uma nota sobre o Bloco Mágico. In Ed. standard bras., vol. XIX. Rio de Janeiro: Imago, 1996b (CD Rom).

GHOSH, P. Google's Vint Cerf warns of "digital Dark Age”. San Jose: BBC News. 3 February 2015. Disponível em: http://www.bbc.com/news/science-environment31450389.

LACAN, J. O seminário: livro 11: os quatro conceitos fundamentais da psicanálise. Rio de Janeiro: Jorge Zahar, 1985a

LACAN, J. O seminário: livro 20: mais ainda. Rio de Janeiro: Jorge Zahar, 1985b. 
MALRAUX, A. O museu imaginário. Lisboa: Edições 70, 2011.

ORLANDI, E. P. A contrapelo: incursão teórica na tecnologia - discurso eletrônico, escola, cidade. RUA [online]. 2010, no. 16. Volume 2.

PÊCHEUX, M. A análise de discurso: três épocas. In GADET, F. e HAK, T (orgs.). Por uma análise automática do discurso. Campinas: Ed. Unicamp, 1990.

PÊCHEUX, M et al. Papel da memória. Campinas: Pontes Editores, 1999.

ROSE, N. Inventando nossos eus. In Silva, T. T. da. Nunca fomos humanos. Belo Horizonte: Autêntica, 2001.

ROSENGARTEN, R. Entre memória e documento. Lisboa: Fundação de Arte Moderna e Contemporânea, Coleção Berardo. Série Coleção Sem Título/Museu Coleção Berardo, nº 6, 2012.

TOSETTO, G. M. Entre arte e documento: as fotografias da Mídia Ninja e a cultura da convergência. In Revista Estúdio, Vol.6 (11): 31-38, 2015. 


\section{Para citar essa obra:}

ANDRADE, E. R. ALMOZARA, P.C. S.A construção da memória do sujeito contemporâneo a partir de arquivos monumentos. In: RUA [online]. $\mathrm{n}^{\circ}$. 22. Volume 1, p. 45-62 - ISSN 1413-2109 - Junho/2016. Consultada no Portal Labeurb - Revista do Laboratório de Estudos Urbanos do Núcleo de Desenvolvimento da Criatividade.

http://www.labeurb.unicamp.br/rua/

Capa: CESTARI, C. Ato Milhões de máscaras, 05/11/2013. Fonte: Página da Mídia Ninja no Facebook.

Laboratório de Estudos Urbanos - LABEURB

Núcleo de Desenvolvimento da Criatividade - NUDECRI

Universidade Estadual de Campinas - UNICAMP

http://www.labeurb.unicamp.br/

Endereço:

LABEURB - LABORATÓRIO DE ESTUDOS URBANOS

UNICAMP/COCEN / NUDECRI

CAIXA POSTAL 6166

Campinas/SP - Brasil

CEP 13083-892

Fone/ Fax: (19) 3521-7900

Contato: http://www.labeurb.unicamp.br/contato 